\title{
HPLC method with monolithic column for simultaneous determination of irbesartan and hydrochlorothiazide in tablets
}

\author{
AMER M. ALANAZI \\ ALI S. ABDELHAMEED \\ NASR Y. KHALIL \\ AZMAT A. KHAN \\ IBRAHIM A. DARWISH* \\ Department of Pharmaceutical Chemistry \\ College of Pharmacy, King Saud University \\ P.O. Box 2457 Riyadh, 11451 \\ Kingdom of Saudi Arabia
}

\begin{abstract}
A simple, sensitive and accurate HPLC method with high throughput has been developed and validated for the simultaneous determination of irbesartan (IRB) and hydrochlorothiazide (HCT) in combined pharmaceutical dosage forms. The proposed method employed, for the first time, a monolithic column in the analysis. Optimal chromatographic separation of the analytes was achieved on Chromolith ${ }^{\circledR}$ Performance RP-18e column using a mobile phase consisting of phosphate buffer $(\mathrm{pH} 4) /$ acetonitrile (50:50, $V / V)$ pumped isocratically at a flow rate of $1.0 \mathrm{~mL}$ $\mathrm{min}^{-1}$. The eluted analytes were monitored with a UV detector set at $270 \mathrm{~nm}$. Under the optimum chromatographic conditions, linear relationship with a good correlation coefficient $(R \geq 0.9997)$ was found between the peak area and the corresponding concentrations of both IRB and HCT in the ranges of 10-200 and 1-20 $\mathrm{ng} \mathrm{mL}^{-1}$. The limits of detection were 2.34 and $0.03 \mathrm{ng} \mathrm{mL^{-1 }}$ for IRB and HCT, respectively. The intra- and inter-assay precisions were satisfactory as the RSD values did not exceed $3 \%$. The accuracy of the proposed method was $>97 \%$. The proposed method had high throughput as the analysis involved a simple procedure and a very short run-time of $<3 \mathrm{~min}$. The results demonstrated that the method is applicable in the quality control of combined pharmaceutical tablets containing IRB and HCT.
\end{abstract}

Keywords: irbesartan, hydrochlorothiazide, HPLC-UV, monolithic column 1,3-diazaspiro[4.4]non-1-en-4-one, Fig. 1], is the first member of a new class of non-peptide long acting angiotensin II receptor antagonists, used worldwide in the treatment of hypertension (1). IRB exerts its action mainly via a selective blockade action on AT1 receptors and the consequent reduced pressure effect of angiotensin II (2). Hydrochlo-

\footnotetext{
* Correspondence; e-mail: idarwish@ksu.edu.sa
} 


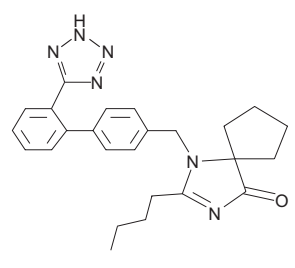

Irbesartan (IRB)

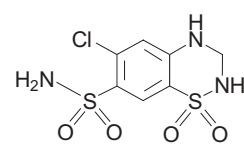

Hydrochlorothiazide $(\mathrm{HCT})$

Fig. 1. Chemical structures of irbesartan (IRB) and hydrochlorothiazide (HCT).

rothiazide (HCT, 6-chloro-3,4-dihydro-2H-1,2,4-benzothiadiazine-7-sulfonamide-1,1-dioxide, Fig. 1), is a well-known diuretic of the benzothiadiazine class (3). Both IRB and HCT may be used alone or in combination with or without other antihypertensive agents. A combination dosage form of IRB and HCT is indicated for the treatment of edema and hypertension. Clinical studies of IRB/HCT suggest that this combination is clinically effective with a favorable safety profile (4). The IRB/HCT combination provided consistent reduction of blood pressure and tolerability regardless of age, obesity, prevalence of type II diabetes as well as greater efficacy in patients at high cardiovascular risk (5).

Several methods have been reported for the determination of IRB in its dosage forms. The methods include spectrophotometry (6), spectrofluorimetry $(7)$, voltammetry $(8,9)$ and HPLC (10). Similarly, several methods have been reported for the analysis of HCT in its single or combined dosage forms. These methods include spectrophotometry (11), spectrofluorimetry $(12)$, voltammetry $(13), \operatorname{HPLC}(14,15)$ and capillary electrophoresis (16). Simultaneous determination of IRB and HCT in combined dosage forms has been achieved by derivative spectrophotometry $(17,18), \operatorname{HPTLC}(19)$ and HPLC (20-24). All these methods suffered from the main drawback of limited throughput because of the inherent limited property of spectrophotometry, multiple and time-consuming steps in HPTLC and the relatively long run time in HPLC methods. Therefore, these methods could not fulfill the requirement of fast analytical procedures with high throughput that could provide a same-day turnaround of results from large numbers of samples in pharmaceutical quality control laboratories. For these reasons, an alternative method with high throughput was required for simultaneous determination of IRB and HCT.

Monolithic HPLC columns, because of their excellent resolution power even at elevated flow rates, have been widely used for separation of multi-component pharmaceutical preparations as efficient alternatives for the conventional reversed phase columns (25). In general, higher flow rate with fast analysis time reduces the consumption of solvents. Another benefit of monolithic columns is water tolerance. According to the manufacturers' information, monolith columns can be used under $100 \%$ aqueous conditions. This property can be useful when more hydrophilic compounds are to be analyzed or if the column is to be loaded with a larger aqueous sample $(25,26)$. An extensive literature review revealed that monolithic columns have not been employed in the HPLC simultaneous determination of IRB and HCT so far. For these reasons, the present study was devoted to employ the monolithic column, for the first time, in the development of a new HPLC method with high throughput for the simultaneous analysis of IRB and HCT in combined dosage forms. 


\section{EXPERIMENTAL}

\section{Chemicals and reagents}

Irbesartan and hydrochlorothiazide reference standards (purity $\geq 99.5 \%$ ) were purchased from Sigma Chemical Co. (USA). Avalide ${ }^{\circledR}$ tablets (Sanofi Aventis, France) labeled to contain $300 \mathrm{mg}$ IRB and $25 \mathrm{mg}$ HCT were procured from the local market. HPLC-grade solvents were purchased from Merck (Germany). Phosphate buffer solution ( $\mathrm{pH}$ 4) was prepared by dissolving disodium hydrogen orthophosphate and potassium dihydrogen orthophosphate in distilled water, adjusting the $\mathrm{pH}$ to $4.0 \pm 0.1$ with glacial acetic acid, and completing the volume. Deionized water was purified using a water purification system ((Milli-Q Labo, Millipore Ltd., USA). Ultra-pure water of $18 \mu \Omega$ was obtained from Milli-Q plus purification system (Millipore Co., USA).

\section{Preparation of standard solutions}

Stock solutions of IRB and HCT $\left(1.0 \mathrm{mg} \mathrm{mL}^{-1}\right)$ were prepared in deionized distilled water. The working standard solution was prepared by diluting aliquots $(1 \mathrm{~mL})$ of stock solutions in 10-mL volumetric flasks with deionized water to give concentrations of 100 $\mu \mathrm{g} \mathrm{mL} \mathrm{m}^{-1}$ for both IRB and HCT. All working solutions were stored at $4{ }^{\circ} \mathrm{C}$ until analysis. Further dilutions were made on the day of analysis to obtain suitable working solutions for each drug.

\section{Preparation of tablet solutions}

Twenty Avalide ${ }^{\circledR}$ tablets were weighed and the average tablet mass was calculated. Tablets were crushed to a fine powder, and a quantity of powdered tablets, equivalent to $30 \mathrm{mg}$ of IRB and $2.5 \mathrm{mg}$ HCT, was transferred into a $10-\mathrm{mL}$ volumetric flask. Five mL of methanol was added, the contents of the flask were shaken for $15 \mathrm{~min}$ with a mechanical shaker, and the volume was then completed to $10 \mathrm{~mL}$ with methanol. The resulting solution was filtered through a $0.45-\mu \mathrm{m}$ membrane filter and the first portion of the filtrate was discarded. This filtrate was diluted, as neccessary, with the mobile phase and subjected to the analysis by the developed method.

\section{HPLC system and chromatographic conditions}

HPLC apparatus consisted of a Waters Beeze ${ }^{\mathrm{TM}}$ system (Waters Corporation, USA) equipped with a 1525 binary pump with on-line degasser, $717+$ autosampler, $5 \mathrm{CH}$ thermostated column compartment and 2487 UV dual wavelength absorbance detector. Chromatographic separations were performed on a Chromolith ${ }^{\circledR}$ Performance RP-18e column (100 $\mathrm{mm} \times 4.6 \mathrm{~mm}$ i.d.) manufactured by Merck KGaA (Germany). The column temperature was kept constant at $25 \pm 2{ }^{\circ} \mathrm{C}$. Separations were performed in isocratic mode. The mobile phase used for separation consisted of phosphate buffer $(\mathrm{pH} 4)$ /acetonitrile $(50: 50, V / V)$ pumped at a flow rate of $1.0 \mathrm{~mL} \mathrm{~min}^{-1}$. The mobile phase was filtered with a Millipore vacuum filtration system equipped with a $0.45-\mu \mathrm{m}$ pore size filter, degassed by ultrasonication, and further by bubbling with helium gas. The samples (10 $\mu \mathrm{L}$ each) 
A. M. Alanazi et al.: HPLC method with monolithic column for simultaneous determination of irbesartan and hydrochlorothiazide in tablets, Acta Pharm. 64 (2014) 187-198.

were injected with the aid of an auto-sampler. The UV detector was set at $270 \mathrm{~nm}$. The system control and on-line data acquisition were performed using Waters Breeze software (Waters). The relation between the peak areas of IRB and HCT and their concentrations was used as the basis for quantification.

\section{General procedure and construction of the calibration curve}

Calibration standards of IRB (10, 30, 50, 70, 100, 120, 150 and $\left.200 \mathrm{ng} \mathrm{mL}^{-1}\right)$ and HCT $\left(1,3,5,7,10,12,15\right.$ and $\left.20 \mathrm{ng} \mathrm{mL}^{-1}\right)$ were prepared by dilution of working standard solutions with the mobile phase. Ten $\mu \mathrm{L}$ of each calibration sample was injected into the HPLC system. Eight-point calibration curves were constructed by plotting the peak area of IRB and HCT vs. the concentrations of each IRB and HCT. Three concentrations, 30, 70 and $150 \mathrm{ng} \mathrm{mL} \mathrm{m}^{-1}$ for IRB and 3, 7, $15 \mathrm{ng} \mathrm{mL}^{-1}$ for HCT, were chosen as quality control samples for each analyte as low, medium and high quality control (QC) samples. Analysis of calibration samples including the QC samples at each concentration was performed in triplicate. Slopes, intercepts, and correlation coefficients $(R)$ were calculated for each analyte by regression analysis.

\section{Method validation}

The proposed method was fully validated in terms of sensitivity, linearity, selectivity, accuracy, intra- and inter-day precision, and system suitability. Method validation was conducted according to recommendations of the International Conference on Harmonisation (ICH) (27) and the guidelines of the Food and Drug Administration (FDA) for validation of analytical procedures and methods (28).

Linearity and sensitivity. - Using the aforementioned optimum chromatographic conditions, three independent calibration curves were constructed correlating the calculated peak area of IRB and HCT vs. their corresponding concentrations. Calibration plots for IRB and HCT were prepared daily at eight concentration points; each concentration was injected in triplicate.

Limits of detection and quantitation. - The limit of detection (LOD) and limit of quantitation $(L O Q)$ were calculated according to the ICH guidelines for validation of analytical procedures (27) based on the standard deviation of the response and the slope of the calibration curve using the formula: $L O D$ or $L O Q=\kappa \times \mathrm{SD}_{\mathrm{a}} / b$, where $\kappa=3.3$ for $L O D$ and 10 for $L O Q, \mathrm{SD}_{\mathrm{a}}$ is the standard deviation of the intercept, and $b$ is the slope of the calibration curve.

Accuracy and precision - quality control (QC) samples. - Intra-day accuracy and precision were assessed by repeated analysis of IRB and HCT. The analysis run consisted of the calibration curve and six replicates at three concentration levels (low, medium, and high) of each analyte. These concentrations were 30, 70 and $150 \mathrm{ng} \mathrm{mL}^{-1}$ for IRB, and 3, 7 and $15 \mathrm{ng} \mathrm{mL}^{-1}$ for HCT. Inter-day accuracy and precision were assessed by analyses of the same samples on three consecutive days.

Robustness and ruggedness. - In order to measure the extent of method robustness, the most critical parameters were interchanged within the range of $1-10 \%$ of the optimum recommended conditions while keeping the other parameters unchanged, and in parallel the chromatographic profile was observed and recorded. The studied parame- 
ters were: the composition of the mobile phase, $\mathrm{pH}$, flow rate, and column temperature. Ruggedness of the method was determined using the mobile phase components from two different manufacturers, two different analysts, and two different instruments.

RESULTS AND DISCUSSION

\section{Method development}

The chromatographic conditions (composition of the mobile phase, its $\mathrm{pH}$, and its flow rate) were optimized through several trials to achieve the best possible resolution, sensitivity and symmetric peak shapes for both IRB and HCT. Different combination ratios of phosphate buffer at different $\mathrm{pH}$ and acetonitrile were tested. The best chromatographic parameters were achieved when a mixture of phosphate buffer $(\mathrm{pH} 4)$ and acetonitrile in a ratio of 50:50 ( V/V) was employed as a mobile phase, and its flow rate was $1.0 \mathrm{~mL} \mathrm{~min}^{-1}$. The highest sensitivity for both IRB and HCT was achieved when the detector was set at $270 \mathrm{~nm}$. Under such optimum chromatographic conditions, IRB and HCT were detected at retention times of 2.23 and $1.75 \mathrm{~min}$, respectively; the total chro-

a)

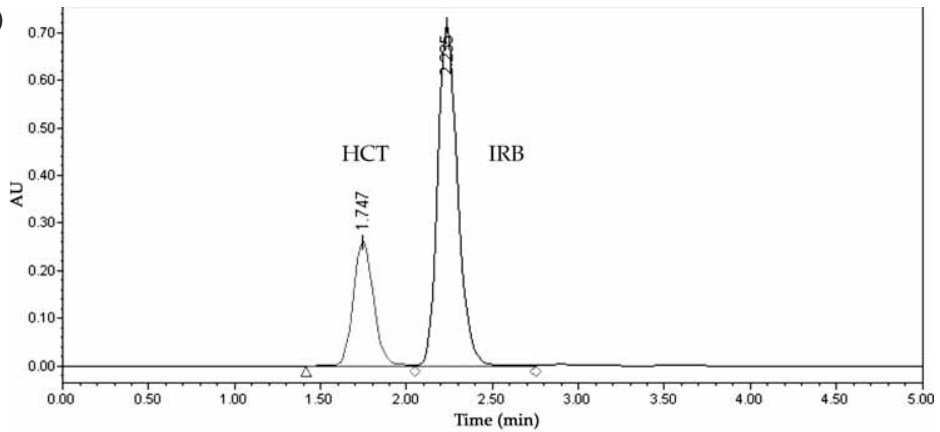

b)

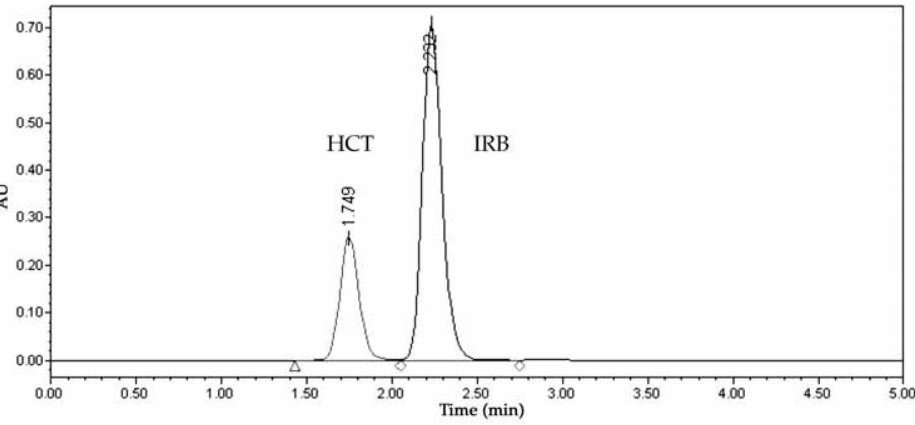

Fig. 2. Representative chromatograms of: a) laboratory-made mixture containing 300 and $25 \mathrm{ng} \mathrm{mL}^{-1}$ of IRB and HCT and b) solution of extracted tablet containing 300 and $25 \mathrm{ng} \mathrm{mL}^{-1}$ of IRB and HCT. 
A. M. Alanazi et al.: HPLC method with monolithic column for simultaneous determination of irbesartan and hydrochlorothiazide in tablets, Acta Pharm. 64 (2014) 187-198.

Table I. Analytical and chromatographic parameters of the proposed HPLC method

\begin{tabular}{lcc}
\hline Parameter & HCT & IRB \\
\hline Chromatography retention time $(\mathrm{min})$ & 1.747 & 2.23 \\
Capacity factor $\left(k^{\prime}\right)$ & 0.75 & 1.23 \\
Tailing factor $(T)$ & 1.09 & 1.19 \\
Number of theoretical plates $(N)$ & 1130 & 1854 \\
Asymmetry at $10 \%$ of peak height & 1.13 & 1.31 \\
Resolution $\left(R_{\mathrm{s}}\right)$ & - & 2.27 \\
Linearity range $\left(\mathrm{ng} \mathrm{mL}^{-1}\right)$ & $1-20$ & $10-200$ \\
Slope \pm RSD $(\%)$ & $438992 \pm 0.7$ & $86741 \pm 0.8$ \\
Intercept $\pm \mathrm{RSD}(\%)$ & $69128 \pm 5.0$ & $143266 \pm 4.3$ \\
Correlation coefficient $(\mathrm{R})$ & 0.9997 & 0.9998 \\
LOD $(\mathrm{ng} \mathrm{mL}-1)$ & 0.03 & 2.34 \\
LOQ $(\mathrm{ng} \mathrm{mL}-1)$ & 1.00 & 7.70 \\
\hline
\end{tabular}

matographic run time was $3 \mathrm{~min}$. The representative chromatogram of IRB and HCT in a laboratory mixture is shown in Fig. 2, and the chromatographic parameters are given in Table I.

\section{Method validation}

Linearity and sensitivity. - Table I summarizes the analytical parameters of the proposed method for simultaneous determination of IRB and HCT. Under the optimum conditions, linear relationships with good correlation coefficients $(R=0.9997,3$ repeated injections per each concentration level) were found between the peak area of each of IRB and HCT vs. their corresponding concentrations in the range of 10-200 and 1-20 ng mL-1 for IRB and HCT, respectively. The high $R$ values were indicative of good linearity, and low deviations of the intercept and the slope were indicative of the reliability of calibration points.

The limit of detection (LOD) and the limit of quantitation $(L O Q)$ for IRB and HCT were 2.34 and $0.03 \mathrm{ng} \mathrm{mL}^{-1}$, and 7.70 and $1.00 \mathrm{ng} \mathrm{mL}^{-1}$, respectively.

Precision and accuracy at three varying concentrations of IRB (30, 70 and $\left.150 \mathrm{ng} \mathrm{mL} \mathrm{m}^{-1}\right)$ and HCT (3, 7 and $\left.15 \mathrm{ng} \mathrm{mL}^{-1}\right)$ were within the acceptable limits (Table II). The proposed method gave satisfactory results in terms of the intra- and inter-day precision as the RSD \% values did not exceed 1.3 and $2.5 \%$ for IRB and HCT, respectively (Table II). Also, the accuracy of the method, namely analytical recovery, ranged from 99.1-105.7 and 99.0-100.6\% for IRB and HCT, respectively (Table II).

Precision and accuracy. - In evaluating the robustness, it was found that a small variation in one parameter did not significantly affect the results; recovery values were 96.4-101.1 \% for IRB and 97.6-101.5\% for HCT (Table III). This indicated reliability of the proposed method during its routine application for the simultaneous determination of IRB and HCT in combined dosage forms. 
A. M. Alanazi et al.: HPLC method with monolithic column for simultaneous determination of irbesartan and hydrochlorothiazide in tablets, Acta Pharm. 64 (2014) 187-198.

Table II. Model accuracy and precision of the proposed method

\begin{tabular}{|c|c|c|c|c|c|c|c|c|c|c|c|c|}
\hline \multirow[b]{3}{*}{ Conc. (ng $\mathrm{mL}^{-1}$ ) } & \multicolumn{6}{|c|}{ Intra-day } & \multicolumn{6}{|c|}{ Inter-day } \\
\hline & \multicolumn{3}{|c|}{ IRB } & \multicolumn{3}{|c|}{ HCT } & \multicolumn{3}{|c|}{ IRB } & \multicolumn{3}{|c|}{ HCT } \\
\hline & 30.00 & 070.00 & 150.00 & 3.00 & 7.00 & 15.00 & 30.00 & 070.00 & 150.00 & 3.00 & 7.00 & 15.00 \\
\hline Accuracy (recovery, \%) & 99.7 & 99.5 & 99.6 & 99.1 & 102.6 & 99.5 & 100.6 & 699.5 & 99.0 & 99.6 & 105.7 & 99.3 \\
\hline Precision (RSD, \%) & 0.2 & 0.4 & 0.4 & 0.4 & 0.5 & 0.3 & 1.3 & 0.6 & 0.2 & 0.6 & 2.5 & 0.8 \\
\hline
\end{tabular}

Ruggedness of the proposed method was evaluated as the relative standard deviation, which did not exceed $2 \%$ (Table III).

The obtained recovery values along with the data obtained from the ruggedness and robustness studies reflected the reproducibility of the analytical results acquired by the proposed method.

Table III. Robustness and ruggedness of the proposed HPLC method for simultaneous determination of IRB and HCT

\begin{tabular}{|c|c|c|}
\hline \multirow{2}{*}{ Parameter } & \multicolumn{2}{|c|}{ Recovery $( \pm \mathrm{SD}, \%)^{\mathrm{a}}$} \\
\hline & IRB & HCT \\
\hline \multicolumn{3}{|c|}{ Robustness } \\
\hline The recommended condition ${ }^{b}$ & $98.1 \pm 1.1$ & $101.5 \pm 1.5$ \\
\hline \multicolumn{3}{|c|}{ Ratio of phosphate buffer/acetonitrile $(\%, V / V)$} \\
\hline $48: 52$ & $99.5 \pm 1.2$ & $98.0 \pm 1.6$ \\
\hline $52: 48$ & $100.6 \pm 0.8$ & $101.2 \pm 1.1$ \\
\hline \multicolumn{3}{|l|}{$\mathrm{pH}$ of the mobile phase } \\
\hline 3.9 & $101.1 \pm 1.2$ & $99.3 \pm 1.1$ \\
\hline 4.1 & $96.4 \pm 1.3$ & $99.8 \pm 0.9$ \\
\hline \multicolumn{3}{|l|}{ Flow rate $(\mathrm{mL} \mathrm{min}-1)$} \\
\hline 0.9 & $98.4 \pm 0.6$ & $102.1 \pm 1.0$ \\
\hline 1.1 & $100.1 \pm 1.5$ & $97.6 \pm 1.2$ \\
\hline \multicolumn{3}{|c|}{ Ruggedness } \\
\hline Analyst-1 & $99.0 \pm 0.5$ & $100.5 \pm 1.3$ \\
\hline Analyst-2 & $98.2 \pm 1.1$ & $98.3 \pm 1.3$ \\
\hline Analyst-3 & $100.3 \pm 1.1$ & $101.3 \pm 1.8$ \\
\hline Day-1 & $99.0 \pm 1.5$ & $99.2 \pm 1.7$ \\
\hline Day-2 & $97.1 \pm 1.5$ & $100.0 \pm 1.3$ \\
\hline Day-3 & $99.3 \pm 1.9$ & $98.0 \pm 1.1$ \\
\hline
\end{tabular}

a Values are mean of 3 determinations.

$\mathrm{b}$ The recommended conditions were given in the Experimental section. 
A. M. Alanazi et al.: HPLC method with monolithic column for simultaneous determination of irbesartan and hydrochlorothiazide in tablets, Acta Pharm. 64 (2014) 187-198.

Chromatographic parameters. - Chromatographic parameters related to the developed method must be within the system suitability limits before sample analysis can commence. The capacity factor $\left(k^{\prime}\right)$, injection repeatability, tailing factor $(T)$, theoretical plate number $(N)$ and resolution $\left(R_{\mathrm{s}}\right)$ for the principal peaks were evaluated using a mixture containing 120 and $10 \mathrm{ng} \mathrm{mL}^{-1}$ of IRB and HCT, respectively. The obtained values are given in Table I. These results assured the suitability of the proposed HPLC method for routine simultaneous analysis of IRB and HCT.

Specificity. - The chromatogram demonstrated the specificity of the proposed method, since there were no peaks at the retention times of IRB and HCT from excipients commonly co-formulated in their combined tablets; the chromatogram of the tablet solution was typically the same as that of the standard solutions (Fig. 2).

Stability. - Stability of both IRB and HCT at room temperature $\left(25 \pm 2{ }^{\circ} \mathrm{C}\right)$ and in the autosampler was assessed by injecting their solutions into the chromatographic system under the optimized conditions at varying time intervals and the peak areas were determined. It was found that both drugs gave constant peak areas; the relative standard deviations were $0.5-1.3 \%$. This result indicated that both IRB and HCT were stable at room temperature for 6 and $24 \mathrm{~h}$ on the bench top and in the autosampler, respectively. The results obtained from samples stored at ambient temperature and in the refrigerator for two to three weeks did not vary significantly (RSD $=2 \%$ ) which indicated the stability of the samples during the period of analysis.

\section{Applications of the method to the analysis of tablets}

It is evident from the aforementioned results that the proposed method gives satisfactory results with the analysis of IRB and HCT in their bulk forms. Tablets containing both drugs (300 and $25 \mathrm{mg}$ of IRB and HCT, respectively) were subjected to the analysis by the proposed method. The values were $301.47 \pm 2.34$ and $25.01 \pm 0.18 \mathrm{mg}$ for IRB and HCT, respectively. These results were compared with those obtained from the reference method (29) by statistical analysis with respect to accuracy (by $t$-test) and precision (by F-test). No significant differences were found between the calculated and theoretical values of $t$ - and $F$-tests at $95 \%$ confidence level, proving similar accuracy and precision in the simultaneous determination of IRB and HCT by both methods (Table IV). This acceptable value indicated the accuracy of the method and its applicability for the routine quality control of IRB-HCT combined tablets without interference from the excipients (Fig. 2).

Table IV. Determination of IRB and HCT in combined tablets by the proposed and reference methods

\begin{tabular}{|c|c|c|c|c|}
\hline \multirow{2}{*}{ Analyte $^{a}$} & \multicolumn{2}{|c|}{ Found $(\mathrm{mg})^{\mathrm{b}}$} & \multirow{2}{*}{$t$-value ${ }^{c}$} & \multirow{2}{*}{$F$-value ${ }^{c}$} \\
\hline & Proposed method & Reference method (29) & & \\
\hline IRB & $301.47 \pm 2.34$ & $300.82 \pm 1.63$ & 1.38 & 3.91 \\
\hline $\mathrm{HCT}^{\circledR}$ & $25.01 \pm 0.18$ & $24.95 \pm 1.43$ & 0.15 & 4.51 \\
\hline
\end{tabular}

a Label claim was 300 and $25 \mathrm{mg}$ for IRB and HCT, respectively.

b Values are the mean of five determinations \pm SD.

c The tabulated $t$ - and $F$-values at $95 \%$ confidence limit are 2.31 and 6.61, respectively. 


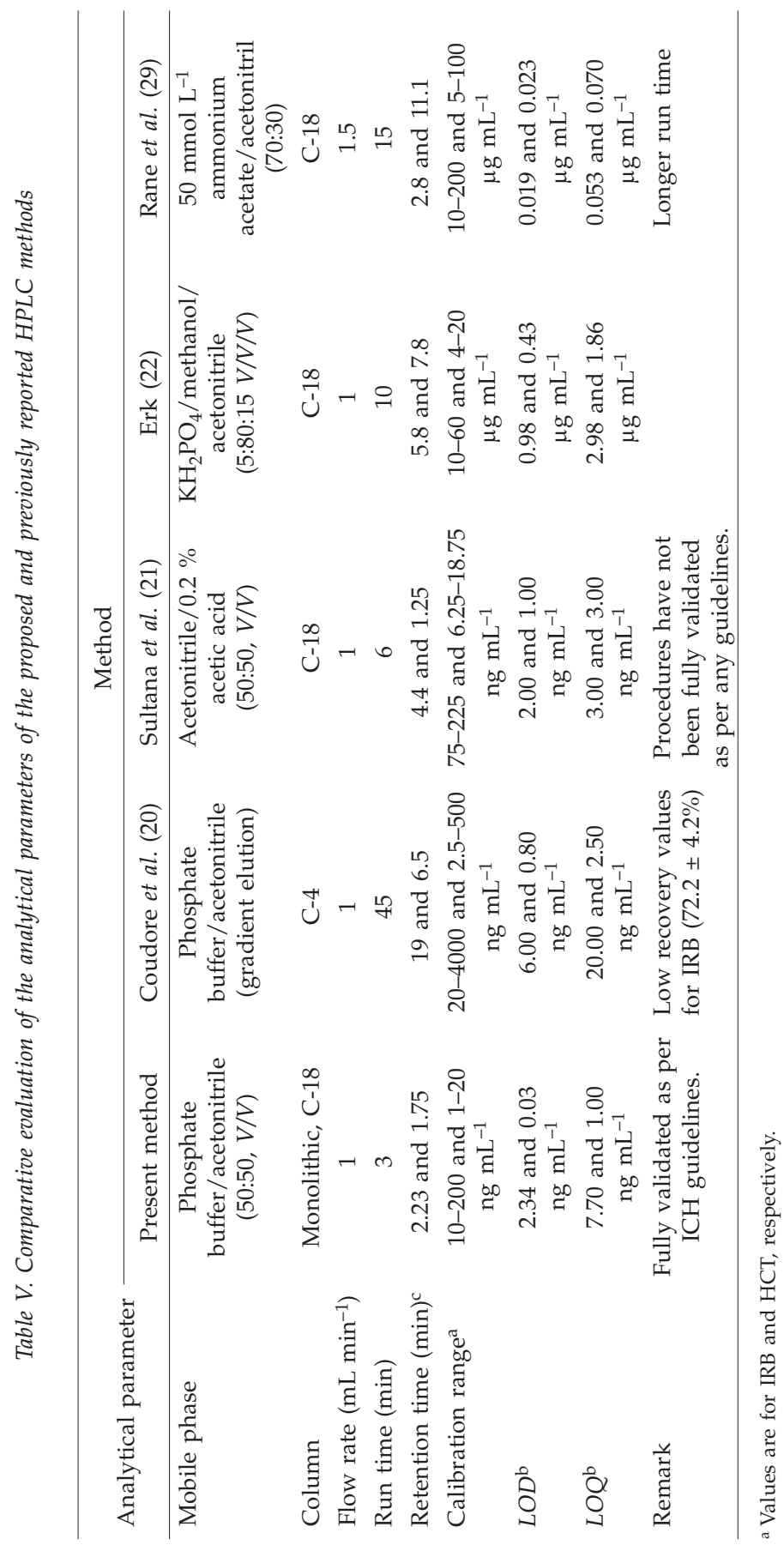


A. M. Alanazi et al.: HPLC method with monolithic column for simultaneous determination of irbesartan and hydrochlorothiazide in tablets, Acta Pharm. 64 (2014) 187-198.

\section{Advantages of the proposed method over the previously reported HPLC methods}

The analytical performance of the method described herein was compared with those of the previously reported HPLCs; the comparative parameters are given in Table V. In terms of the analytical throughput, derived from the chromatographic run, the method described herein has the shortest run time among the previously reported methods (20-22, 29), since the retention times of IRB and HCT were 2.23 and $1.75 \mathrm{~min}$, respectively. This short run time gives the present method a high-throughput property and makes it capable to analyze a large number of samples in a reasonable period of time in pharmaceutical quality control laboratories. In comparison with the method developed by Coudore et al. (20), which employed gradient elution of the mobile phase components over $45 \mathrm{~min}$, this long time leads to consumption of large volumes of expensive organic solvents and decreases the method throughput, as well. In contrast, the method described herein employs the simplest isocratic elution mode for a very short time $<3$ min, which saves the organic solvents consumption and increases the analysis throughput. Also, the method described herein has shorter run time than the method described by Rane et al. (29) which was 15 min. Furthermore, the method described here demonstrated higher recovery values (99.1-105.7 \% and 99.0-100.6 \% for IRB and HCT, respectively) compared to those obtained by the previous method $(72.2 \pm 4.2$ and $106.0 \pm 8.0 \%$ for IRB and HCT, respectively). The method described herein has been fully validated according to the guidelines of ICH rather than the method described by Sultana et al. (21) which has not been validated at all. The present method also shows higher sensitivity than that achieved by Erk (22). In addition, the previous method was not applied to the analysis of combined dosage forms for IRB and HCT.

\section{CONCLUSIONS}

The present study represents the first report that deals with the employment of the monolithic column in the development of an HPLC method for the determination of IRB and HCT in their combined pharmaceutical tablets. The proposed method showed acceptable accuracy, precision, selectivity and linear concentration ranges. Statistical analysis of the results proved that the method is suitable for simultaneous determination of IRB and HCT in tablets forms without any interference from the excipients. The simple procedure involved in sample preparation and the short run-time $(<3 \mathrm{~min})$ added the important property of high throughput to the method. This property enables the method to process a large number of samples in pharmaceutical quality control laboratories.

Acknowledgments. - The authors extend their appreciation to the Deanship of Scientific Research at King Saud University for funding this work through research group No. RGP-VPP-203. 
A. M. Alanazi et al.: HPLC method with monolithic column for simultaneous determination of irbesartan and hydrochlorothiazide in tablets, Acta Pharm. 64 (2014) 187-198.

\section{REFERENCES}

1. S. Miura, S. S. Karnik and K. Saku, Review: Angiotensin II type 1 receptor blockers: class effects versus molecular effects, J. Renin-Angiotensin-Aldosterone Sys. 12 (2011) 1-7; DOI: 10.1177/ 1470320310370852.

2. M. Burnier and H. R. Brunner, Angiotensin II receptor antagonists, Lancet 355 (2000) 637-645; DOI: 10.1016/S0140-6736(99)10365-9.

3. A. Lant, Diuretic drugs progress in clinical pharmacology, Drugs 31 (1986) 40-55; DOI: 10.2165/ 00003495-198600314-00006.

4. J. M. Neutel, E. Saunders, G. L. Bakris, W. C. Cushman, K. C. Ferdinand, E. O. Ofili, J. R. Sowers and M. A. Weber, The efficacy and safety of low- and high dose fixed combinations of irbesartan/hydrochlorothiazide in patients with uncontrolled systolic blood pressure on monotherapy: The inclusive trial, J. Clin. Hyperten. 7 (2005) 578-586; DOI: 10.1111/j.1524-6175.2004.04720.x.

5. M. R. Weir, J. M. Neutel, A. Bhaumik, M. E. D. Obaldia and P. Lapuerta, The efficacy and safety of initial use of irbesartan/hydrochlorothiazide fixed-dose combination in hypertensive patients with and without high cardiovascular risk, J. Clin. Hyperten. 9 (2007) 23-30; DOI: 10.1111/ j.1524-6175.2007.07805.x.

6. H. E. Abdellatef, Extractive-spectrophotometric determination of disopyramide and irbesartan in their pharmaceutical formulation, Spectrochim. Acta A 66 (2007) 1248-1254; DOI: 10.1016/j. saa.2006.06.015.

7. S. R. El-Shaboury, S. A. Hussein, N. A. Mohamed and M. M. El-Sutohy, Spectrofluorimetric method for determination of some angiotensin II receptor antagonists, J. Pharm. Biomed. Anal. 2 (2012) 12-18; DOI: 10.1016/j.jpha.2011.10.005.

8. B. Bozal, B. Doğan-Topal, B. Uslu, S. A. Özkan and H. Y. Aboul-Enein, Quantitative analysis of irbesartan in pharmaceuticals and human biological fluids by voltammetry, Anal. Lett. 42 (2009) 2322-2338; DOI: 10.1080/00032710903137491.

9. I. H. I. Habib, S. A. Weshahy, S. Toubar and M. M. A. El-Alamin, Adsorptive stripping voltammetric determination of irbesartan in bulk and pharmaceutical products, Pharm. Chem. J. 42 (2008) 438-442; DOI: 10.1007/s11094-008-0144-4.

10. S.-Y. Chang, D. B. Whigan, N. N. Vachharajani and R. Patel, High-performance liquid chromatographic assay for the quantitation of irbesartan (SR 47436/BMS-186295) in human plasma and urine, J. Chromatogr. B 702 (1997) 149-155; DOI: 10.1016/S0378-4347(97)00387-3.

11. E. Martín, O. Hernández, F. Jiménez and J. J. Arias, Simultaneous spectrophotometric determination of hydrochlorothiazide and pharmaceutical preparations, Anal. Lett. 28 (1995) 1449-1464; DOI: 10.1080/00032719508006406.

12. M. Omar, Spectrophotometric and spectrofluorimetric determination of certain diuretics through ternary complex formation with eosin and lead (II), J. Fluoresc. 20 (2010) 275-281; DOI: 10.1007/ s10895-009-0551-2.

13. B. Rezaei and S. Damiri, Multiwalled carbon nanotubes modified electrode as a sensor for adsorptive stripping voltammetric determination of hydrochlorothiazide, Sensors J. IEEE 8 (2008) 1523-1529; DOI: 10.1109/jsen.2008.923585.

14. G. Carlucci, G. Palumbo, P. Mazzeo and M. Giovanna Quaglia, Simultaneous determination of losartan and hydrochlorothiazide in tablets by high-performance liquid chromatography, J. Pharm. Biomed. Anal. 23 (2000) 185-189; DOI: 10.1016/S0731-7085(00)00268-5.

15. M. Kartal and N. Erk, Simultaneous determination of hydrochlorothiazide and amiloride hydrochloride by ratio spectra derivative spectrophotometry and high-performance liquid chromatography, J. Pharm. Biomed. Anal. 19 (1999) 477-485; DOI: 10.1016/S0731-7085(98)00241-6. 
A. M. Alanazi et al.: HPLC method with monolithic column for simultaneous determination of irbesartan and hydrochlorothiazide in tablets, Acta Pharm. 64 (2014) 187-198.

16. S. Hillaert, K. De Grauwe and W. Van den Bossche, Simultaneous determination of hydrochlorothiazide and several inhibitors of angiotensin-converting enzyme by capillary electrophoresis, J. Chromatogr. A 924 (2001) 439-449; DOI: 10.1016/S0021-9673(01)00714-2.

17. J. Joseph-Charles, S. Brault, C. Boyer, M. H. Langlois, L. Cabrero and J. P. Dubost, Simultaneous determination of irbesartan and hydrochlorothiazide in tablets by derivative spectrophotometry, Anal. Lett. 36 (2003) 2485-2495; DOI: 10.1081/al-120024337.

18. C. Vetuschi, A. Giannandrea, G. Carlucci and P. Mazzeo, Determination of hydrochlorothiazide and irbesartan in pharmaceuticals by fourth-order UV derivative spectrophotometry, Farmaco 60 (2005) 665-670; DOI: 10.1016/j.farmac.2005.04.013.

19. A. S. Khodke, L. V. Potale, M. C. Damle and K. G. Bothara, A validated stability indicating HPTLC method for simultaneous estimation of irbesartan and hydrochlorothiazide, Pharm. Methods 1 (2010) 39-43; DOI: 10.4103/2229-4708.72229.

20. F. Coudoré, L. Harvard, S. Lefeuvre, E. M. Billaud, P. Beaune, G. Bobrie, M. Azizi, P. Prognon and S. Laurent, HPLC-DAD Analysis of hydrochlorothiazide and irbesartan in hypertensive patients on fixed-dose combination therapy, Chromatographia 74 (2011) 559-565; DOI: 10.1007/ s10337-011-2111-6.

21. N. Sultana, M. S. Arayne, S. S. Ali and S. Sajid, Simultaneous determination of olmesartan medoxomil and irbesartan and hydrochlorothiazide in pharmaceutical formulations and human serum using high performance liquid chromatography, Chin. J. Chromatogr. 26 (2008) 544-549; DOI: $10.1016 /$ S1872-2059(08)60029-2.

22. N. Erk, Simultaneous determination of irbesartan and hydrochlorothiazide in human plasma by liquid chromatography, J. Chromatogr. B 784 (2003) 195-201; DOI: 10.1016/S1570-0232(02) 00759-6.

23. L. F. Tutunji, M. F. Tutunji, M. I. Alzoubi, M. H. Khabbas and A. I. Arida, Simultaneous determination of irbesartan and hydrochlorothiazide in human plasma using HPLC coupled with tandem mass spectrometry: Application to bioequivalence studies, J. Pharm. Biomed. Anal. 51 (2010) 985-990; DOI: 10.1016/j.jpba.2009.10.023.

24. Z. Vujić, N. Mulavdić, M. Smajić, J. Brborić and P. Stanković, Simultaneous analysis of irbesartan and hydrochlorothiazide: An improved HPLC method with the aid of a chemometric protocol, Molecules 17 (2012) 3461-3474; DOI: 10.3390/molecules17033461.

25. F. Gerber, M. Krummen, H. Potgeter, A. Roth, C. Siffrin and C. Spoendlin, Practical aspects of fast reversed-phase high-performance liquid chromatography using $3 \mu \mathrm{m}$ particle packed columns and monolithic columns in pharmaceutical development and production working under current good manufacturing practice, J. Chromatogr. A 1036 (2004) 127-133; DOI: 10.1016/j.chroma. 2004.02.056.

26. R. Plumb, G. Dear, D. Mallett and J. Ayrton, Direct analysis of pharmaceutical compounds in human plasma with chromatographic resolution using an alkyl-bonded silica rod column, Rapid Commun. Mass Spectrom. 15 (2001) 986-993; DOI: 10.1002/rcm.329.

27. International Conference on Harmonisation of Technical Requirements for Registration of Pharmaceuticals for Human Use, ICH Harmonised Tripartite Guideline, Validation of Analytical Procedures: Text and Methodology Q2(R1), Current Step 4 version, Geneve November 2005; http://www.ich.org/fileadmin/Public_Web_Site/ICH_Products/Guidelines/Quality/Q2_R1/ Step4/Q2_R1_Guideline.pdf; January 9, 2014.

28. Department of Health and Human Services, Food and Drug Administration, Maryland, USA, Analytical Procedures and Methods Validation, Chemistry, Manufacturing, and Controls Documentation., US FDA, Silver Spring (MD), August 2000; http://www.fda.gov/downloads/Drugs/ Guidances/ucm122858.pdf; January 9, 2014.

29. V. P. Rane, K. R. Patil, J. N. Sangshetti, R. D. Yeole and D. B. Shinde, Stability indicating LC method for simultaneous determination of irbesartan and hydrochlorothiazide in pharmaceutical preparations, J. Chromatogr Sci. 48 (2010) 595-600; DOI: 10.1093/chromsci/48.7.595. 